\title{
Predator-prey body size relationship in temporary wetlands: effect of predatory insects on prey size spectra and survival
}

\author{
Fabián Gastón Jara \\ Laboratorio de Fotobiología, INIBIOMA, CONICET-Universidad Nacional Comahue, Quintral 1250, Bariloche, Argentina
}

Received 7 October 2015; Accepted 2 March 2016

\begin{abstract}
The effect of predators on prey size structure in aquatic communities has been well studied in lentic permanent habits, but less attention has been placed on temporary environments. The biota of seasonal Andean wetlands in Patagonia is basically formed by crustaceans, insects and pond-breeding amphibians. The dominant predators in these wetlands are macroinvertebrates, mostly aquatic insects. The main objectives of this study were to examine the seasonal and interannual variation in the body size of prey and predators in two temporary wetlands located in northwest Patagonia, during two consecutive hydroperiods and to evaluate the effect of different insect predators over different prey sizes and different ontogenetic stages of invertebrate and vertebrate prey. Prey size structure and predator size structure were affected by the wetland type and the sampling months and predator body size was not correlated with prey size structure. The experiments showed that small prey were the most impacted by predaceous insects and all predators showed size-limited predation. Although aquatic insects significantly reduced the number of prey in the predation experiments, they did not significantly affect the body size structure of prey in nature. In this sense, the diversity of aquatic insects with different predatory strategies could maintain the heterogeneity in prey size structure in the wetlands studied.
\end{abstract}

Key words: Andean wetlands / prey size structure / predator size / prey ontogeny / aquatic insects

\section{Introduction}

Food web interactions in aquatic ecosystems depend strongly on body size. With increasing body size, food habits and susceptibility to predators change dramatically (Stein et al., 1988). Predators that feed selectively on certain prey sizes can affect the size distribution of prey populations (Peckarsky, 1982; Cooper et al., 1985; Cronin and Travis, 1986). In permanent freshwater systems, predation by vertebrates (firstly by large fish) regulates the dynamics and body size structure of permanent aquatic ecosystems (Wellborn et al., 1996). Fish predation can affect all the components of permanent ecosystems, from zooplankton to large macroinvertebrates (Wellborn et al., 1996). However, in temporary aquatic ecosystems that are naturally fish-free, salamanders exert keystone predation in all places where they are distributed (Morin, 1983; Alford, 1989). Since temporary freshwater wetlands in South America do not have salamanders, the top predation is exerted by invertebrate predators that

Corresponding author: fjara77@gmail.com seasonally colonize the wetlands. Several authors have shown that top invertebrate predators have a strong effect on fishless pond ecosystems, in some cases producing a trophic cascade (Wilbur, 1997; Stav et al., 2000; Cobbaert et al., 2010). Gape-limited predators such as salamanders can show completely different effects on the community in comparison with non-gape-limited predators like aquatic insects (Maret and Collins, 1996; Wilbur, 1997). For gapelimited predators, prey vulnerability is a function of prey size relative to predator size, and this disparity in size, rather than abundance of prey alone, determines whether or not prey can be caught or eaten by a predator (Smith and Petranka, 1987; Dong and Polis, 1992; Maret and Collins, 1996).

Because aquatic insects are generalist predators, they eat a variety of prey based on both what is available and what they can grasp. This includes a variety of snails (Gastropoda), seed shrimp (Ostracoda), copepods (Copepoda), amphipods, marsh-beetle larvae (Scirtidae), mayflies (Trichoptera), mosquito larvae and amphibian larvae (Wilbur, 1987; Lundkvist et al., 2003). Some aquatic insects such as large water bugs and diving beetles are voracious and versatile predators that can have a large 
impact on prey populations (Turner and Chislock, 2007; Ohba et al., 2008; Cobbaert et al., 2010). Cannibalism has also been documented for the predaceous insects such as the adult stage of belostomatids or backswimmers, and the largest dragonfly larvae have been observed feeding on conspecific larval stages. This in part helps to explain why nymphs are often found in areas where adults are not (Hampton, 2004).

The position of predators in the trophic food web is influenced by abiotic and biotic variables. For example, the body size relationship between predators and their prey is the main variable that influences their feeding efficiency (Peckarsky, 1982; Cooper et al., 1985; Cronin and Travis, 1986; Formanowicz, 1986; Nyström and Perez, 1998). Experimental evidence suggests that ontogenetic changes in body size can alter the effect of predatorprey interactions (Alford, 1989; Wilbur and Fauth, 1990; Cohen et al., 1993; Urban, 2007). In some cases, the typical representation of size-dependent predation risk assumed in theoretical literature or represented in simplified experiments may not match the dynamics found in natural systems (Wilbur, 1987; Skelly, 2002; Urban, 2007). Because most studies are theoretical models or simplified experiments, evidence from field systems is necessary to evaluate the premises upon which the predator-prey size theory is based (Persson et al., 1996; Woodward and Hildrew, 2002). In some cases, predatory insects predate on the largest prey available as they use poison or toxins. When predatory insects colonize the wetland during the spring, they must find suitable prey size; however, if the adequate prey size available is scarce, then this is often compensated with cannibalistic behavior (Lancaster and Briers, 2008).

Seasonal wetlands in Andean forests and prairie lands called "mallines", which constitute $5 \%$ of the Argentine Patagonia, constitute freshwater reservoirs and refuges for native and even endemic species (Vega, 1995, 1999, 1998; Vega and Balseiro, 1994; Diaz-Villanueva and Trochine, 2005; Perotti et al., 2005; Trochine et al., 2008; Cuassolo et al., 2012; Jara, 2014). The dynamics and composition of the aquatic biota in wetlands have only recently begun to be studied with the objective of developing urgent conservation measures (Epele and Miserendino, 2015a, 2015b). The prey components of these successional communities are snails, crustaceans, caddisfly larvae, and anuran tadpoles, which constitute the primary consumer trophic level (Jara et al., 2012, 2013). It is possible that the body size structure and life stages of both prey and predators of these communities vary from year to year, probably in relation with characteristics of the hydroperiod (Jara, 2014).

The main objective of this research was to study how the body size affects the predator-prey interaction in temporary Andean wetlands. This was achieved by analyzing (a) the variation in body size structure between wetlands along the hydroperiod, (b) the influence of the body size of aquatic insect predators on the body size spectra of prey and (c) the size-dependent survival of prey.

\section{Methods}

\section{Natural history of the wetlands studied}

The two temporary wetlands studied, Fantasma and Llao Llao, are protected areas in Bariloche, Río Negro, Argentina. In a typical year, Fantasma wetland dries up in late December or early January. In contrast, Llao Llao wetland is usually completely dry by the end of January, but might occasionally have water all year round. The environmental features of each wetland are detailed in Table 1. Both wetlands are supplied by springs and runoff and typically refill with rainfall (late April-May). Their bottoms are primarily muddy and homogeneous throughout. According to the classification of Williams (2006), both are seasonal wetlands because they alternate wet periods with dry periods and drought is predictable. The macrophyte species found in Fantasma wetland were Potentilla anserina, Carex aematorrhyncha and Puccinellia glaucescens (Trochine et al., 2008), whereas those found in Llao Llao were Juncus bufonius, Juncus procerus, Carex aematorrhyncha and Eleocharis macrostachya among others (Jara et al., 2013). The two wetlands are covered with ice during the winter and the frozen surface lasts until August. Amphibians in the area are typically pondbreeding anurans of the South American temperate forest (Formas, 1981). The species in the area reproduce during the spring or summer, and the tadpoles of some species overwinter in the wetland for one year.

\section{Communities sampled}

Predaceous insects and prey in each wetland were sampled monthly from August to January. Pond-net sweeping for a fixed time period was used to determine richness and body size-distribution of prey and predators. This type of technique has been used in streams (RIVPACS (River InVertebrate Prediction And Classification System), Wright et al., 2000) and ponds (PSYM, the Predictive SYstem for Multimetrics; Biggs et al., 2000). A 50- $\mu \mathrm{m}$ mesh dipnet was used $\left(36 \times 25 \mathrm{~cm}^{2}\right.$ mouth opening) in the vegetated areas during the daytime. The samples collected were poured into a white plastic tray and examined to estimate relative density. Predaceous insects were classified as diving beetles, dragonfly larvae, belostomatids and backswimmers because they differ in microhabitat use and foraging behavior (Lancaster and Downes, 2013). The relative density of each species was classified into three categories - low density: less than 30 individuals captured, medium density: from 30 to 50 individuals captured, and high density: more than 50 individuals captured. For large-size species $(\geq 5 \mathrm{~mm})$, total length of prey and predators (not including spines, urogomphi or cerci) was measured in situ with an electronic digital caliper (nearest $0.1 \mathrm{~mm}$ ). A minimum of ten individuals of each species, randomly selected from the homogenized sample of all available individuals, were measured for each wetland on each sampling date. For small species such as 
Table 1. Environmental features of the studied wetlands.

\begin{tabular}{lcccccc}
\hline Wetland & $\begin{array}{c}\text { Latitude and } \\
\text { longitude }\end{array}$ & $\begin{array}{c}\text { Elevation } \\
(\mathrm{m} . \mathrm{a} . \mathrm{s} .1)\end{array}$ & Area $\left(\mathrm{m}^{2}\right)$ & Depth $(\mathrm{m})$ & $\begin{array}{c}\mathrm{pH} \\
\text { Mean }( \pm 1 \text { SEM })\end{array}$ & $\begin{array}{c}\text { Conductivity }\left(\mu \mathrm{S} . \mathrm{cm}^{-\mathrm{T}}\right) \\
\mathrm{Mean}( \pm 1 \text { SEM})\end{array}$ \\
\hline Llao Llao & $41^{\circ} 2^{\prime} \mathrm{S} ; 71^{\circ} 33^{\prime} \mathrm{W}$ & 821 & 1571.5 & 0.36 & $7.16(1)$ & $95.51(9.98)$ \\
Fantasma & $41^{\circ} 5.6^{\prime} \mathrm{S} ; 71^{\circ} 27^{\prime \prime} \mathrm{W}$ & 794 & 10000 & 1.6 & $7.22(0.22)$ & $99.86(6.11)$ \\
\hline
\end{tabular}

zooplankton, one sample of $5 \mathrm{~L}$ of filtered water was fixed and carried to the laboratory to record their size under a stereomicroscope. The different species of zooplankton, including ostracods, were identified to genus or species level. Zooplankton body size spectra were separated in two groups, copepods and cladocerans, because both prey have different swimming capacities that may influence their susceptibility to predation. Additionally, the differences among zooplankton species were relatively small (from 0.5 to $3 \mathrm{~mm}$ ) as compared with other herbivorous species such as amphipods, which showed large variation in body size (from 1 to $11 \mathrm{~mm}$ ). Rare species, i.e., those found only once during the sampling, were not taken into account for this study.

\section{Experiments}

\section{General set-up}

The predaceous diving beetle larvae Lancetes flavipes and Rhantus antarcticus and the water bug Belostoma bifoveolatum were selected as predators because they reached high abundances and colonized the wetlands during the sampling years. All the predators used in the experiments were collected during October 2013 using a hand net. Each predator was placed in a $250-\mathrm{mL}$ plastic cup containing tap water and mosquito larvae as a food source. The cups were kept in a walk-in environmental chamber set to $18^{\circ} \mathrm{C}$, with alternating $12 \mathrm{~h}$ of light and $12 \mathrm{~h}$ of dark. At least $24 \mathrm{~h}$ prior to the start of each experiment, all predators were removed from the cups and held in plastic tubes without prey to standardize hunger levels. The prey used in the experiments were primary consumers from the selected wetlands and included: the cladoceran Daphnia commutata, the snail Biomphalaria peregrina, the amphipod Hyalella patagonica, marshbeetle larvae (Scirtidae), and Pleurodema thaul tadpoles.

\section{Experiment I: survival of small prey components}

The objective of this experiment was to measure the survival of the small components at the primary consumer level found in the wetlands studied. An assortment of prey was introduced in 20 experimental units. Six small and six large D. commutata, six Scirtidae larvae and six $H$. patagonica were placed in each of the 20 units. Then, three predator species were distributed in each of the 15 experimental units: Rhantus antarcticus beetle larvae in five units, Lancetes flavipes beetle larvae in five units and adult $B$. bifoveolatum in five units. The remaining five units were used as controls without predators to estimate natural mortality. This assortment of prey is frequent and abundant in both wetlands studied and other forest wetlands in the area (Jara et al., 2013; Jara, 2014). Table 2 shows all sizes and stages of the prey and predators used in the experiment.

\section{Experiment II: size-dependent prey survival throughout ontogeny}

The objective of this experiment was to study the interaction along the ontogeny between the largest prey (the snail $B$. peregrina, the amphipod $H$. patagonica and tadpoles of $P$. thaul) and the larger predatory insects that coexist with those prey in the wetlands studied (R. antarcticus larvae (instar III), L. flavipes larvae (instar III) and $B$. bifoveolatum adults). The survival of each prey species was measured in three size classes that represent early, middle and late ontogeny stage. The set-up of the experiment was similar to that of the first experiment, but the ontogenies of all prey were tested separately. Six prey and one predator species were placed in each experimental unit and after $2 \mathrm{~h}$ the prey that were still alive were recorded ( $\%$ survival \pm SE). Five replicates of each prey/ontogenetic stage were maintained without predators as control. Table 2 shows all the sizes and stages of the prey and predators used in the experiment.

\section{Data analyses}

To explore temporal changes in predator and prey body sizes, two-way analysis of variance (ANOVA) was performed in each sampling year, with sampling months (August-December) and wetlands as fixed effects. First assumptions of normality and homoscedasticity were confirmed with Kolmogorov-Smirnov and Levene tests. Only data from August to December were analyzed because this period represents the time of coexistence of both the prey and predators used in the experiments. Bonferroni post-hoc comparisons were used to analyze differences in prey and predator size for each wetland for each sampling month. The Pearson product-moment correlation was used to test if predator body size was related to the body size structure of prey in each wetland during both hydroperiods.

The survival data from the first experiment were analyzed using two-way ANOVA, to evaluate differences in small prey survival with prey species and predator as fixed effects. In the second experiment, differences in prey 
Table 2. Total length (shell diameter in snails) (mean \pm SD) of predators and prey used in the experiments.

\begin{tabular}{|c|c|c|c|}
\hline & Predators & Mean & $\mathrm{SD}$ \\
\hline \multirow[t]{3}{*}{ Experiment I } & Lancetes larvae & 15.40 & 0.52 \\
\hline & Rhantus larvae & 18.85 & 1.5 \\
\hline & Belostoma adults & 23.37 & 0.74 \\
\hline \multirow[t]{3}{*}{ Experiment II } & Lancetes larvae & 16 & 1.2 \\
\hline & Rhantus larvae & 17.5 & 0.9 \\
\hline & Belostoma adults & 22.1 & 0.6 \\
\hline Experiment & Prey & & \\
\hline \multirow[t]{4}{*}{ I: small prey components } & Scirtidae larvae & 5.22 & 0.74 \\
\hline & Small Daphnia & 1.99 & 0.08 \\
\hline & Large Daphnia & 3.1 & 0.13 \\
\hline & Hyalella & 3.70 & 0.56 \\
\hline \multirow[t]{9}{*}{ II: survival during ontogeny } & Hyalella early & 2.65 & 0.59 \\
\hline & Hyalella middle & 7.2 & 0.61 \\
\hline & Hyalella late & 11.61 & 1.08 \\
\hline & Snail early & 4.46 & 0.33 \\
\hline & Snail middle & 6.95 & 0.46 \\
\hline & Snail late & 9.21 & 0.41 \\
\hline & Pleurodema early & 7.24 & 0.54 \\
\hline & Pleurodema middle & 21.35 & 4.65 \\
\hline & Pleurodema late & 42.44 & 2.73 \\
\hline
\end{tabular}

survival were tested by a two-way ANOVA for each predator, with ontogenetic stage (early, middle and late) and prey species (snails, amphipods and tadpoles) as fixed effects. A post-hoc test (Student-Newman-Keuls Method) was done to determine significant differences among treatments $(P<0.05)$. Data were transformed $(\ln$ or $\arcsin \sqrt{ } p$ ) when needed to meet ANOVA requirements. Assumptions of normality and homoscedasticity were confirmed with Kolmogorov-Smirnov and Levene tests. Statistical analyses were performed with SigmaStat 3.5 software at a $95 \%$ significance level.

\section{Results}

\section{Wetland communities}

The communities were relatively different between the two wetlands (Fig. 1). Fantasma wetland showed a larger number of species in all groups except in amphibian larvae. Llao Llao wetland showed a more diverse amphibian assemblage (Fig. 1). Snails were only present in Fantasma wetland and showed a more diverse crustacean assemblage (Fig. 1). Predaceous insects were more diverse in Fantasma wetland, with seven species recorded (Fig. 1). During 2012-2013, the community composition of Fantasma wetland was formed by nine crustacean species, two snail species and three aquatic insects (Fig. 1). Only one amphibian species ( $P$. thaul) and six predaceous insects were found in this wetland (Fig. 1).

Llao Llao wetland included five crustaceans (one copepod species and one cladoceran species, two ostracod species and one amphipod (H. patagonica), two aquatic insects and four amphibian species (Fig. 1). Only three predaceous insects were found in this wetland (Fig. 1).

\section{Body size structure and phenology in the wetlands studied}

Amphipods ( $H$. patagonica) and anuran larvae (Batrachyla taeniata and Batrachyla leptopus) were the first species to colonize Llao Llao wetland. The abundances of both species changed from low to high with the advance of the season (Fig. 2). The body size spectra of amphipods ranged from $1 \mathrm{~mm}$ (newly hatched) to $9.5 \mathrm{~mm}$ (adults), and the large body size dominated during August-September. The mean body size of amphipods was larger in Fantasma wetland than in Llao Llao $(5.16 \pm 3.49$ and $4.1 \pm 2.1 \mathrm{~mm}$, respectively). The amphipod phenology was different in both wetlands: in Fantasma they began to be captured in OctoberNovember, whereas in Llao Llao they were captured early in May-June and with more relative abundance than other prey.

The body size spectra of zooplankton ranged from 1 to $3 \mathrm{~mm}$ in Llao Llao. Zooplankton colonized the wetland in winter and disappeared in September-October. In the Fantasma wetland, the body size spectra of the zooplankton ranged from 1 to $5 \mathrm{~mm}$ (cladocerans $2.2 \pm 0.25 \mathrm{~mm}$, copepods $3.89 \pm 0.37 \mathrm{~mm}$ ). The mean body size of zooplankton was larger in Fantasma than in Llao Llao (no cladocerans were observed) in both hydroperiods (copepods $2.89 \pm 0.12 \mathrm{~mm}$ ). The body size spectra of ostracods was different in each wetland, with larger individuals found in Fantasma wetland (Llao Llao ostracod size spectra $=0.6-1.35 \mathrm{~mm}$, Fantasma ostracod size spectra $=1-3.5 \mathrm{~mm}$ ).

Zooplankton and amphipods were the earliest prey that colonized Fantasma, followed by Pleurodema tadpoles (Fig. 2). The zooplankton in Fantasma developed after the flooding of the wetland, attaining high abundances during spring (Fig. 2). Copepods were always more 


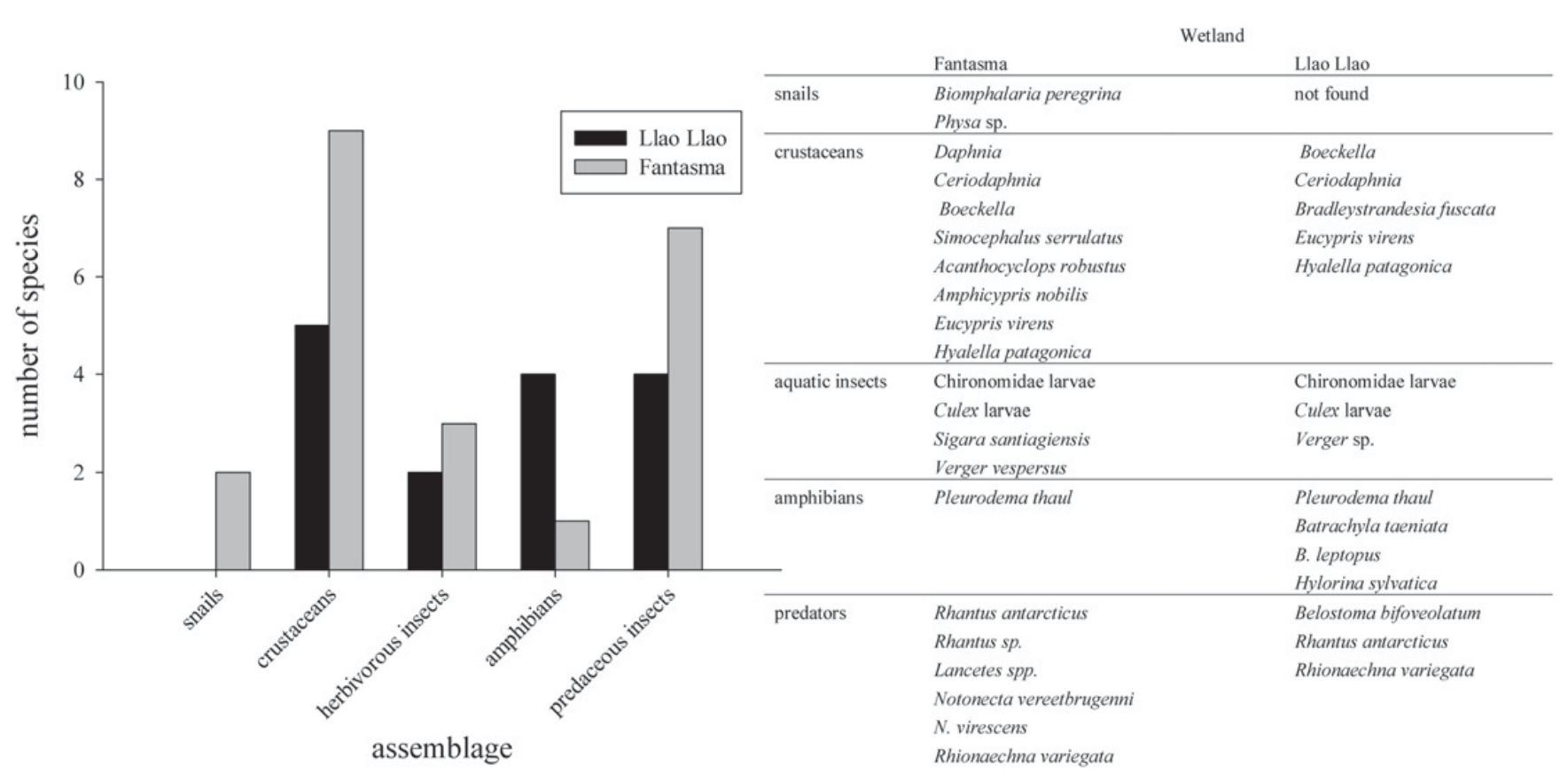

Fig. 1. Number of species found in the wetlands studied during 2012 and 2013. The species were grouped in five categories: snails, crustaceans, herbivorous insects, amphibians and predaceous insects. Additionally, the species for each group are detailed.

abundant than cladocerans during both hydroperiods (Fig. 2). Pleurodema tadpoles were more abundant during 2012 than during 2013 (Fig. 2).

In Llao Llao wetland, diving beetle larvae (Rhantus) and dragonfly larvae (mainly Rhantus variegata) were the first predators to colonize the wetland but these predators showed low and medium abundances during the hydroperiod (Fig. 2). Belostomatids (B. bifoveolatum) colonized the wetland in October and reached high abundances with the advance of the spring, thus becoming the most important predator in this system (Fig. 2). Fantasma wetland showed a similar phenology of predators during the 2 years (Fig. 2). Diving beetles (Ranthus spp. and Lancetes spp) and backswimmers (Notonecta vereertbruggheni and Notonecta virescens) were the first captured aquatic insect predators and their abundances were high during 2012. During 2013, backswimmer abundance was low in all sampling months (Fig. 2).

\section{Body size variation during the hydroperiod}

The ANOVA showed that the body size of prey and predators was affected by the sampling month and wetland. The analysis conducted with data from 2012 showed that both factors (sampling month and wetland) significantly affected prey size distribution and that the interaction between factors was also significant (Table 3). Prey body size was larger in Llao Llao than in Fantasma wetland (Llao Llao mean $=15.53 \pm 1.15 \mathrm{~mm}$, Fantasma mean $=9.25 \pm 1.13 \mathrm{~mm}, P<0.001)$. Llao Llao wetland showed significant differences in prey size between August $v s$. November and August vs. December (Bonferroni $t$ test $P<0.05$ for all comparisons). Fantasma wetland showed differences in prey size in August and September vs. the rest of the sampling months and between OctoberNovember and December (Bonferroni $t$ test $P<0.05$ for all comparisons). Predator body size distribution was also affected by both factors but the interaction was not significant in this case (Table 3). Predator size was significantly larger in Llao Llao wetland than in Fantasma wetland (Llao Llao predator size $=15.59 \pm 0.76$, Fantasma predator size $=11.58 \pm 0.92, P=0.001$ ).

The ANOVA conducted with data from 2013 showed that both factors influenced the body size distribution of prey and predators and in both cases the interaction between factors had a significant effect on body size distribution (Table 3). Prey and predator sizes in Llao Llao wetland were larger than in Fantasma wetland in 2013 (Llao Llao prey size $=16.59 \pm 1.1$, Fantasma prey size $=9.13 \pm 1.2, \quad P<0.001$; Llao Llao predator size $=16.27 \pm 0.62$, Fantasma predator size $=12.28 \pm 0.8, P<0.001)$. Prey size in Llao Llao was different between August, September and October vs. November, December and predator size was significantly different between December vs. the rest of the sampling months $(P<0.05$ for all comparisons). Prey size in Fantasma wetland showed differences between December vs. the rest of the sampling months and predator size showed differences between August and September $v s$. the rest of the sampling months $(P<0.05$ for all comparisons).

Prey body size was not correlated with predator body size in Llao Llao and Fantasma wetlands in either hydroperiod (Pearson correlation $P>0.05$ between variables in 2012 and 2013). During 2012, Llao Llao wetland showed a decrease in the average body size of predators and an increase in the average body size of prey from 


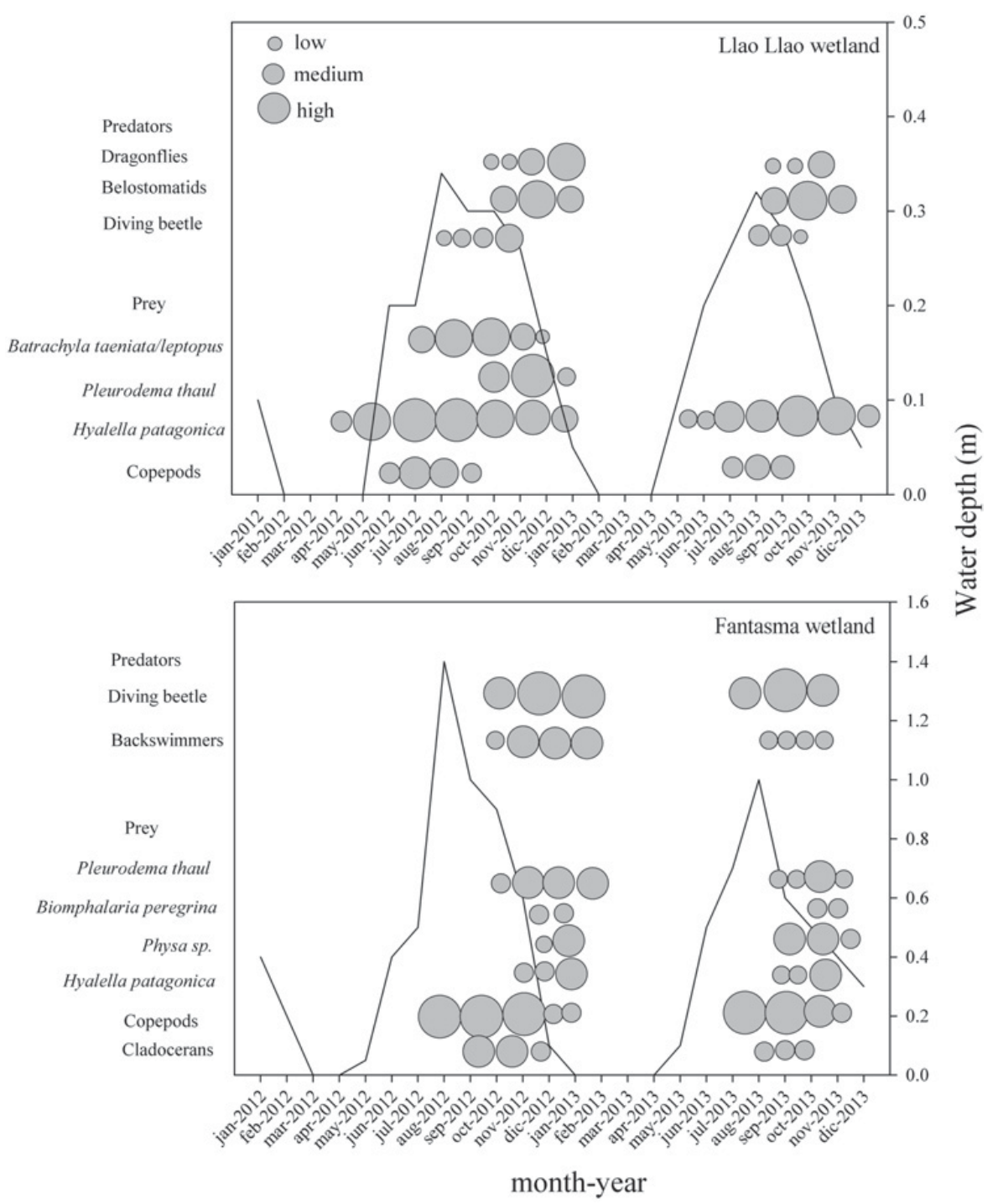

Fig. 2. Relative abundances of predaceous insects and their prey in the Llao Llao and Fantasma wetlands during two consecutive hydroperiods (2012-2013), the black line indicated the water depth of the wetland.

August to December (Fig. 3). The hydroperiod 2013 showed that the average body size of predators and prey increased with the advance of the spring (Fig. 3). However, the correlation between both variables was not significant. Prey and predator body sizes in Fantasma wetland were lower than in Llao Llao for all the months sampled (Fig. 3). The body size of both prey and predators increased with the advance of the hydroperiod in this wetland.

\section{Size-dependent prey survival}

Experiment I: Prey survival in the control treatments was $100 \%$. Therefore, the mortality observed in the experimental units was due to predator effect only. The ANOVA indicated that predator, prey type and their interaction significantly affected the survival of prey (Table 4). All the treatments were different from the control, except the predation of Belostoma over the two daphnia sizes (Fig. 4). The effect of Belostoma differed significantly along the prey factors from the effect of Rhantus and Lancetes, which showed a similar effect on prey survival (Fig. 4). Rhantus effect on the survival of small Daphnia and Hyalella was larger than that on the survival of large Daphnia or Scirtidae larvae, whereas Lancetes affected more the survival of small Daphnia, Hyalella or Scirtidae larvae than that of large Daphnia (Fig. 4).

Experiment II: The two-way ANOVA for Rhantus predators showed that both fixed effects (prey species and ontogenetic stages) significantly affected the survival of prey, but operated independently (Table 4). The pairwise comparison showed differences in survival between Biomphalaria vs. Pleurodema tadpoles and Hyalella amphipods because Rhantus did not predate any ontogenetic stage of Biomphalaria $(P<0.05$ for all comparisons, Fig. 5). Additionally, Rhantus affected more the survival 
Table 3. Summary of two-way analysis of variance (ANOVA) performed to evaluate the effect of wetland and sampling month on prey (a) and predator (b) body size distribution during the hydroperiods 2012 and 2013.

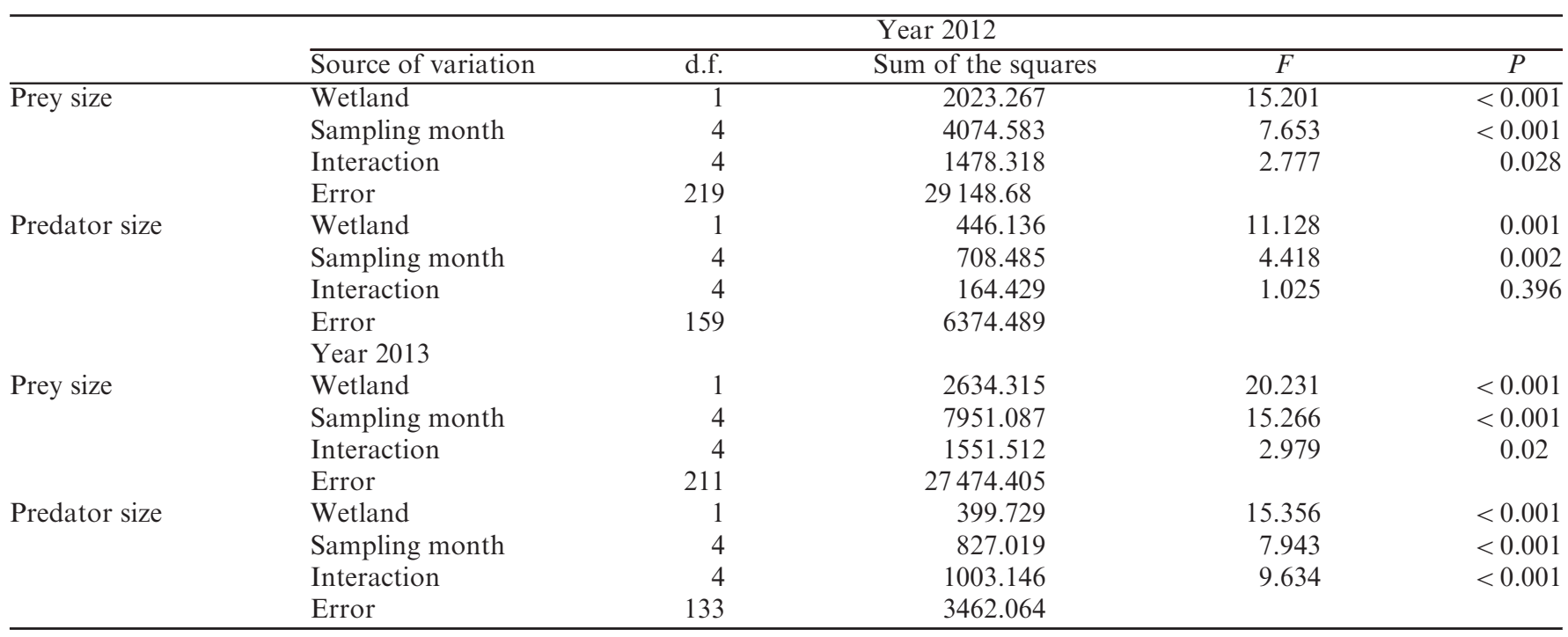

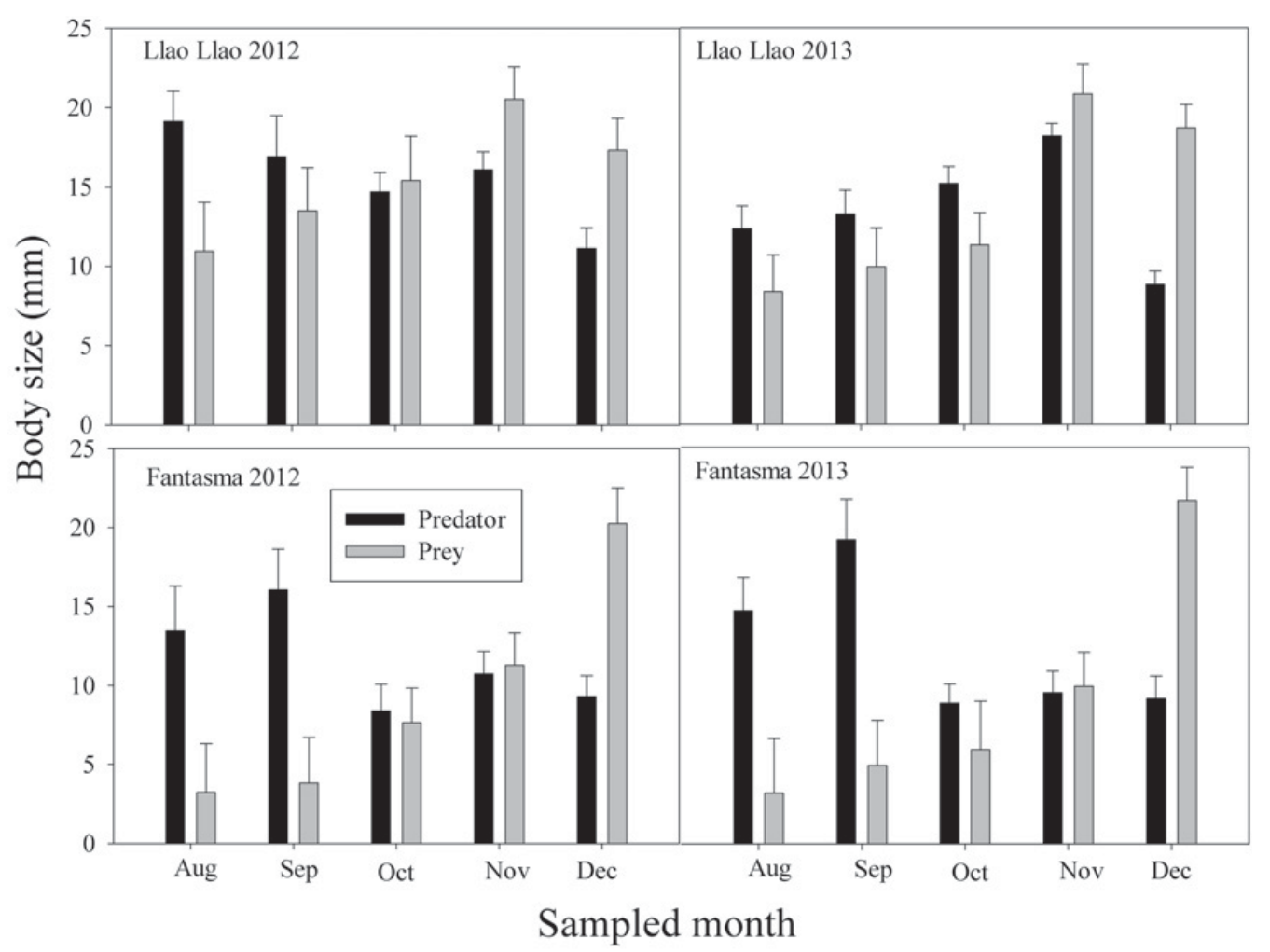

Fig. 3. Body size of prey and predators (mean $\pm \mathrm{SE}$ ) during the sampling months in each wetland during two consecutive hydroperiods (2012-2013).

of amphipods than that of tadpoles $(P<0.05$ amphipods vs. tadpoles).

The two-way ANOVA for Lancetes predators showed that both fixed effects and the interaction between them significantly affected prey survival (Table 4 ). The pairwise comparison showed that Lancetes did not affect the survival of Biomphalaria in any ontogenetic stage
$(P>0.05$ for all comparisons, Fig. 5). Hyalella amphipods and Pleurodema tadpoles showed differences in survival when exposed to Lancetes $(P<0.05)$, with Hyalella the more affected prey (Fig. 5).

The two-way ANOVA for Belostoma predators showed that both fixed effects and the interaction between them significantly affected prey survival (Table 4). 


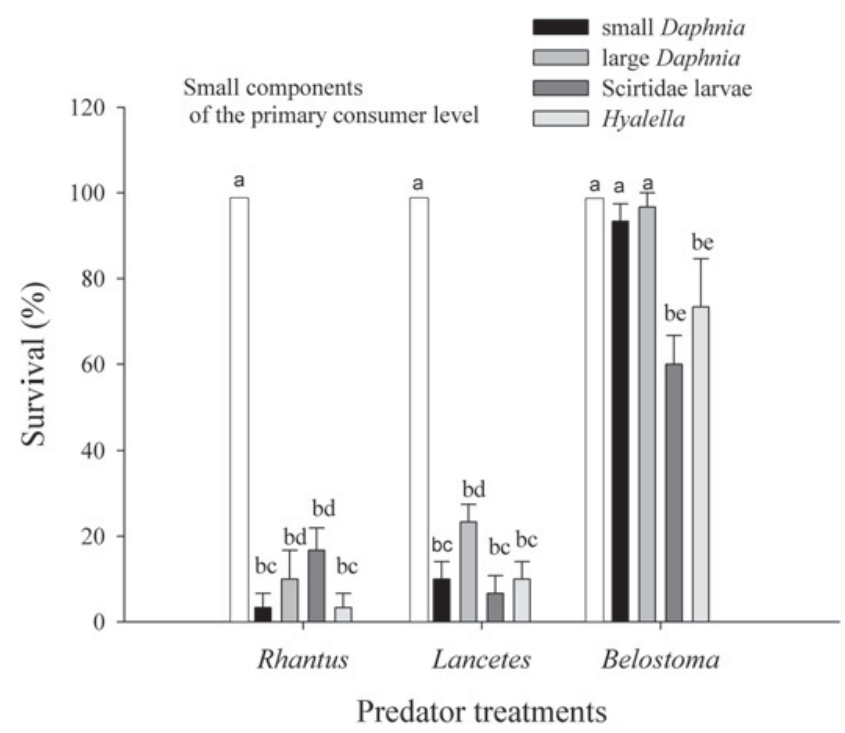

Fig. 4. Survival (\%) of the small prey components exposed to direct predation by three predatory insects. The data are the mean \pm SE of the survival of five replicates for each treatment. The letters above the bar indicate differences among treatments: the first letter indicates differences between control and predator treatments, and the second letter indicates differences among predators.

The pairwise comparison showed differences between Biomphalaria survival vs. that of the two other prey $(P<0.05$ for all comparisons). The survival of Biomphalaria showed differences between early $v s$. middle and late ontogenetic stages $(P<0.05$ for all comparisons, Fig. 5). The survival between Hyalella stages showed no differences, i.e., all stages were equally affected by Belostoma predators $(P>0.05)$. Survival of tadpoles showed significant differences between late $v s$. early and middle ontogenetic stages $(P<0.05$ for all comparisons, Fig. 5). The survival of late tadpole stages to this predator was higher.

\section{Discussion}

This investigation showed differences in the abundances and composition of prey and predaceous insects in two temporary wetlands located in northwest Patagonia. Prey were mainly represented by snails, crustaceans and amphibians, whereas predators were mainly represented by medium-size aquatic insects such as diving beetles, backswimmers, belostomatids and dragonflies. Prey size spectra showed interannual variation and varied with the sampling month. Zooplankton species were the most abundant prey items in Fantasma wetland, while amphibian larvae and amphipods were the most abundant prey in Llao Llao. The predator size spectrum was narrower than the prey body size, and the main body size found in both wetlands was medium size. Belostomatids and diving beetles predominated in Llao Llao wetland in both hydroperiods, while diving beetles and backswimmers were the predators that predominated in Fantasma wetland. Although the experimental data showed that the predatory insects had greater impact on certain prey species and sizes, the field data did not show a strong influence of those predators on prey size structure. In nature, the effect of aquatic insect predators on prey size structure could be decreased by other variables such as habitat complexity, intraguild predation, competition and predatory avoidance strategy of each prey species (Trochine et al., 2006, 2008; Jara, 2014).

The evolution of body size of prey and predators in the wetlands showed some differences between them. The field data are not conclusive about whether the prey or predator body size influences each other. By contrast, the body size spectra of prey were always heterogeneous through the sampling months. However, some patterns were observed from the data. For example, in Fantasma wetland, prey size as well as predator size increased along the hydroperiod, but these variables were not correlated. These patterns in prey body size observed in temporary wetlands could reflect the effect of generalized predators such as aquatic insects, which can eat a wide range of prey size. This was not supported by the results of the feeding experiments, where the predators used predated on different prey size spectra. However, as aquatic insects grow, they can incorporate new prey body sizes in their diet and become more selective for certain types of prey (Ohba, 2009). For example, Cronin and Travis (1986) found that the impact of backswimmers over prey decreases dramatically with the increase in prey size and that they can thus play a size selective role in the community. These results were found for large predatory insects such as dragonflies and diving beetle; however, the size range taken by these predators is broader than smaller ones (Travis et al., 1985; Ohba, 2009). In the present study, the effect of predatory insects that coexist in the wetlands and the size-limited differences observed among those predators could maintain the heterogeneity of prey species and size in the wetlands studied. In this sense, the diversity in predatory strategies could generate a diffuse selection (Urban, 2008) that may result in a heterogeneous prey size structure in the wetlands studied. However, other factors, such as the hydroperiod and the particular phenology of each species, may have a major influence on prey size structure in temporary wetlands. As temporary wetlands are successional communities, they either incorporate or lose species along the hydroperiod (Schneider and Frost, 1996). This can be observed from the abundances recorded in the field. Each species has a particular time of colonization and reproduction that depends on the photoperiod and temperature (Hershey and Lamberti, 2001; Lancaster and Downes, 2013). Therefore, when a new species colonizes the wetland or when this species reproduces in the wetland, the newly hatched individuals and new adults that arrived at the wetland naturally alter the size structure of these aquatic environments.

Predators can generate a divergent selection on prey growth (Urban, 2007). Gape-unconstrained and gape-limited predators can affect the structure of prey size 
Table 4. Summary of two-way analysis of variance (ANOVA) performed for each experiment to evaluate the effect of predation on prey survival.

\begin{tabular}{|c|c|c|c|c|c|}
\hline & Source of variation & d.f. & Sum of the squares & $F$ & $P$ \\
\hline \multirow[t]{4}{*}{ Experiment I } & Prey species & 2 & 66287.037 & 220.277 & $<0.001$ \\
\hline & Predator species & 3 & 2314.815 & 5.128 & 0.004 \\
\hline & Interaction & 6 & 3601.852 & 3.99 & 0.003 \\
\hline & Error & 48 & 7222.222 & & \\
\hline \multicolumn{6}{|l|}{ Experiment II } \\
\hline \multirow[t]{4}{*}{ Predator: Rhantus } & Prey species & 2 & 61086.42 & 224.909 & $<0.001$ \\
\hline & Ontogenetic stage & 2 & 1567.901 & 5.773 & 0.007 \\
\hline & Interaction & 4 & 950.617 & 1.75 & 0.16 \\
\hline & Error & 36 & 4888.889 & & \\
\hline \multirow[t]{4}{*}{ Predator: Lancetes } & Prey species & 2 & 37419.753 & 155.436 & $<0.001$ \\
\hline & Ontogenetic stage & 2 & 2160.494 & 8.974 & $<0.001$ \\
\hline & Interaction & 4 & 1432.099 & 2.974 & 0.032 \\
\hline & Error & 36 & 4333.333 & & \\
\hline \multirow[t]{4}{*}{ Predator: Belostoma } & Prey species & 2 & 5345.679 & 13.968 & $<0.001$ \\
\hline & Ontogenetic stage & 2 & 6271.605 & 16.387 & $<0.001$ \\
\hline & Interaction & 4 & 17209.877 & 22.484 & $<0.001$ \\
\hline & Error & 36 & 6888.889 & & \\
\hline
\end{tabular}

in a different way. For example, vertebrate gape-limited predators have a strong effect on the body size structure of the zooplankton community and the invertebrate benthic community of permanent ponds and lakes (Holomuzki et al., 1994; Winkelmann et al., 2011; Zhang et al., 2013). Here, both wetlands are constituted firstly by gapeunconstrained invertebrate predators like diving beetle larvae, water bugs and dragonfly larvae (Urban, 2007). These gape-unconstrained predators can affect the survival of their prey along the entire ontogeny and some of them like water bugs and dragonfly larvae can grasp prey larger than themselves (Wilbur, 1997; Ohba, 2009). It has also been shown that water bugs and dragonfly larvae can grasp prey larger than themselves (Wilbur, 1997; Ohba, 2009). In the present study, the experiment where different ontogenetic stages of prey were exposed to three kinds of predators showed that the most important factor that affects the predator-prey interaction in these systems is the body size of prey and species. The insect predators investigated can impact the survival of smaller prey such as amphipods during their entire ontogeny and the largest prey such as tadpoles for a short period of their development. These results show that the aquatic insects studied here are size-limited. This was more evident for amphibian larvae, which are the largest prey in the system. This prey showed a low predation effect by aquatic insects in medium and late ontogeny, even when they were exposed to the largest predator (Belostoma). For example, although diving beetle larvae are considered as gapeunconstrained predators, the two diving beetle larvae (Rhantus and Lancetes) were limited by the size of the prey because they predated only on small or medium-size prey like cladocerans, marsh-beetle larvae and small and medium-sized amphipods. Therefore, the condition of being gape limited in aquatic insects might be more related to the body size and specific ontogenetic stage of the predator. Furthermore, the water bug B. bifoveolatum was the only predator that consumed snails during the experiments. Other authors have shown that dragonflies and diving beetles feed on snail species (Turner and Chislock, 2007; Cobbaert et al., 2010). Other works have shown that water bugs are snail predators (Raut and Saha, 1989); thus, their presence could affect the population size structure of snail communities. These results demonstrate that although predaceous insects have been considered as opportunistic predators that feed on a great variety of prey, this is not true for all insect species, at least in the two wetlands studied here.

The effect of other small invertebrate predators present in temporary wetlands of northern Patagonia was studied by Vega (1995), Diéguez and Balseiro (1998), Trochine et al. (2008) and Garcia (2010). These authors found that small invertebrates such as Mesostoma ehrenbergii and the large carnivorous copepod Parabroteas sarsi can influence the structure and dynamics of zooplankton communities. However, the number of prey consumed by these species over $24 \mathrm{~h}$ is significantly lower in comparison with that consumed by large aquatic insects that colonize the temporary wetlands studied here. Additionally, the other species used here as prey, such as small and large daphnids, snails, marsh beetle larvae (Scirtidae) and early instars of amphipods, can be considered the most abundant prey items in the wetlands studied and can be an important food source for aquatic insects, as shown by the results of the prey survival experiments.

The high density of aquatic and semiaquatic vegetation in both wetlands may provide refuge from predation, and can significantly affect prey survival and therefore the size structure of the prey in the presence of predators, as found by other authors (Sredl and Collins, 1992; Tarr and Babbitt, 2002; Hampton, 2004; Trochine et al., 2006). Differences in aquatic vegetation forms and distribution in the wetland may affect predation risk even more than differences in vegetation density (Dionne and Folt, 1991). All predators used in the present study 


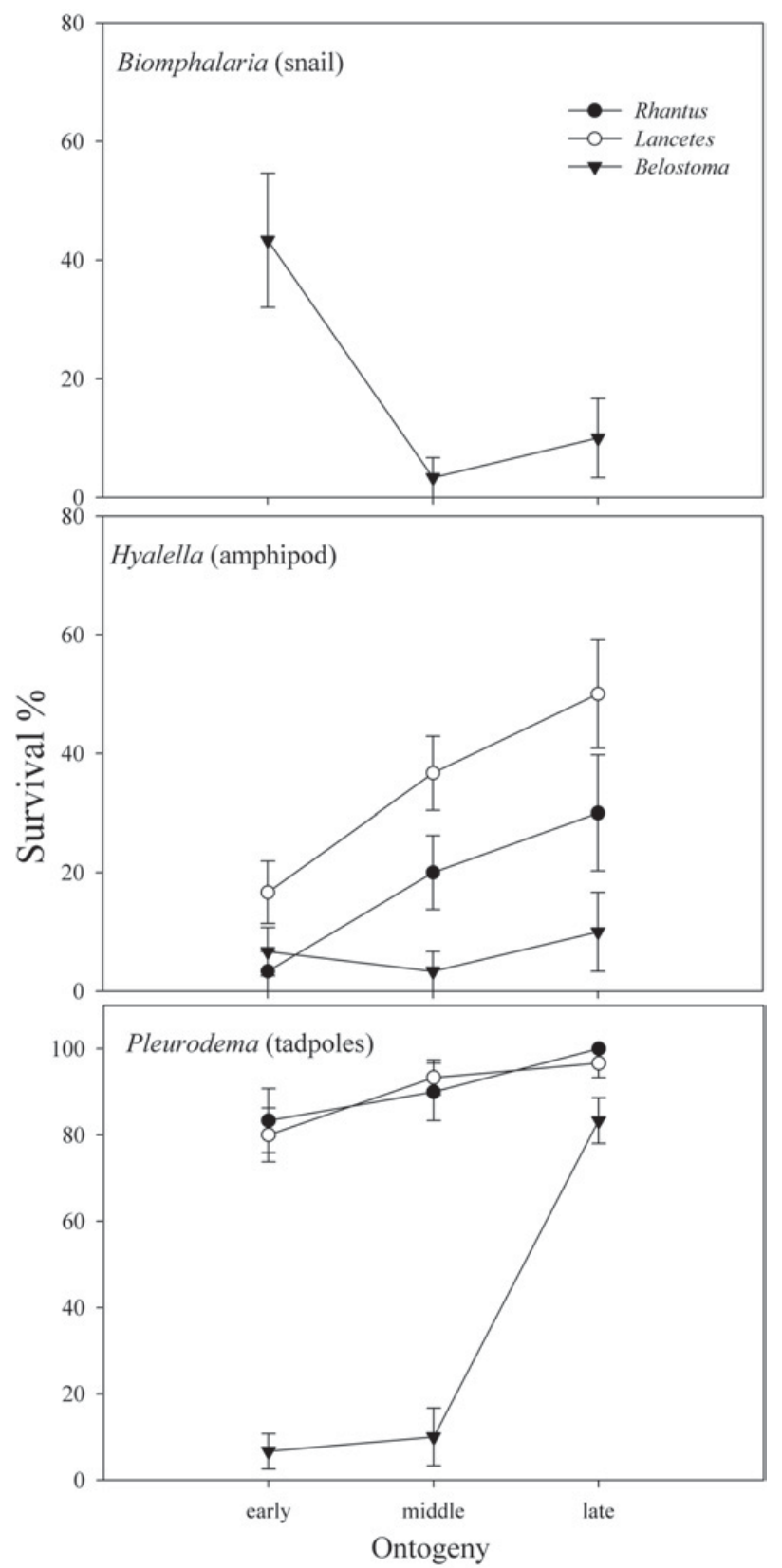

Fig. 5. Survival (\%) of the three ontogenetic stages (early, middle and late ontogeny) of the largest prey exposed to three predatory insects. The data are the mean $\pm \mathrm{SE}$ of the survival of five replicates for each treatment.

use the vegetation to ambush the prey (Jara et al., 2012, 2013). Therefore, the interaction between prey, predators and vegetation in these systems needs to be studied further.

The climatic variation in the region, with highly dry years (total precipitation $895 \mathrm{~mm}$ in 2008) and wet years (2116 mm in 2009), allows the occurrence of several interannual modifications in the phenology of prey and predators, and this could therefore affect the size structure of prey and predators (Jara, 2014). These freshwater environments are ideal to analyze how the climate influences the food web structure and studying them could help develop theoretical models to predict future scenarios. Recently, Gilbert and DeLong (2015) found that the increase in temperature due to climate warming alters the food web body size structure, mainly the predator-prey body size ratios. Temperature could also affect the body size structure in temporary wetlands. For example, the wetlands studied here are situated in the Patagonian region, where a large climate variation can be observed between years. To conclude, the present investigation aids in the interpretation of the relationship between body size of prey and predators inhabiting temporary wetlands. The results showed that the size structure of these temporary environments differs from that of permanent ones. Moreover, the heterogeneous prey body size structure of the wetlands was likely produced by the predation effect of aquatic insects; this assertion is further supported by the survival experiments. The effects of other important variables (e.g., hydroperiod, temperature, etc.) on the structure of prey size in temporary wetlands need further investigation.

Acknowledgements. This investigation was performed under the institutional animal care guidelines established by the Administración de Parques Nacionales of Argentina (APN). Subsecretaria de Medio Ambiente de San Carlos de Bariloche allowed the samplings in Fantasma wetland and Parque Municipal Llao Llao. I thank the two anonymous reviewers who helped improve the manuscript considerably. I am grateful to Coviaga C. and García D. for determining the ostracod and zooplankton species, respectively, and Sganga J. for determining the trichoptera species. This work was funded by UNComa B166 and by a research grant PICT 2011 (Agencia, FONCyT) to F. Jara.

\section{References}

Alford R.A., 1989. Variation in predator phenology affects predator performance and prey community composition. Ecology, 70, 206-219.

Balseiro E.G. and Vega M., 1994. Vulnerability of Daphnia middendorffiana to Parabroteas sarsi predation: the role of the tail spine. J. Plankton Res., 16, 783-793.

Biggs J., Williams P., Whitfield M., Fox G. and Nicolet P., 2000. Biological Techniques of Still Water Quality Assessment: Phase 3. Method Development, Environment Agency, Bristol, UK.

Cobbaert D., Bayley S.E. and Greter J.L., 2010. Effects of a top invertebrate predator (Dytiscus alaskanus; Coleoptera: Dytiscidae) on fishless pond ecosystems. Hydrobiologia, 644, 103-114.

Cohen J.E., Pimm S.L., Yodzis P. and Saldana Y., 1993. Body sizes of animals predators and animal prey in food webs. J. Animal Ecol., 62, 67-78.

Cooper S.D., Smith D.W. and Bence J.R., 1985. Prey selection by freshwater predators with different foraging strategies. Can. J. Fisher. Aquat. Sci., 42, 1720-1732.

Cronin J.T. and Travis J., 1986. Size-limited predation on larval Rana areolata (Anura: Ranidae) by two species of 
backswimmer (Insecta: Hemiptera: Notonectidae). Herpetologica, 42, 171-174.

Cuassolo F., Balseiro E. and Modenutti B., 2012. Alien vs. native plants in a Patagonian wetland: elemental ratios and ecosystem stoichiometric impacts. Biol. invasions, 14, 179-189.

Diaz-Villanueva V. and Trochine C., 2005. The role of microorganisms in the diet of Verger cf. Limnophilus (Trichoptera: Limnephilidae) larvae in a patagonian andean temporary pond. Wetlands, 25, 473-479.

Diéguez M.C. and Balseiro E.G., 1998. Colony size in Conochilus hippocrepis: defensive adaptation to predator stage sizes. Hydrobiologia, 388, 421-425.

Dionne M. and Folt C.L., 1991. An experimental analysis of macrophyte growth forms as fish foraging habitats. Can. J. Fish. Aquat. Sci., 48, 123-131.

Dong Q. and Polis G.A., 1992. The dynamics of cannibalistic populations: a foraging perspective. In: Elgar M.A. and Crespi B.J. (eds.), Cannibalism, Ecology and Evolution Among Diverse Taxa, Oxford University Press, New York, $13-37$.

Epele L.B. and Miserendino M.L., 2015a. Temporal dynamics of invertebrate and aquatic plant communities at three intermittent ponds in livestock grazed Patagonian wetlands. J. Nat. History, 50, 711-730, doi:10.1080/00222933.2015. 1062930.

Epele L.B. and Miserendino M.L., 2015b. Environmental quality and aquatic invertebrate metrics relationships at Patagonian wetlands subjected to livestock grazing pressures. PLoS ONE, 10, e0137873. doi: 10.1371/journal.pone. 0137873.

Formanowicz D.R. Jr., 1986. Anuran tadpole/aquatic insect predator-prey interactions: tadpole size and predator capture success. Herpetologica, 42, 367-373.

Formas J.R., 1981. Adaptaciones larvarias de los anuros del bosque temperado Austral de Sudamérica. Medio Ambiente, $5,15-21$.

García R.D., 2010. Ciclo de vida del copépodo depredador Parabroteas sarsi (Calanoida, Centropagidae) Impacto del canibalismo en la población de la Laguna Fantasma. Licenciatura thesis. San Carlos de Bariloche, Universidad Nacional del Comahue.

Gilbert J.P. and DeLong J.P., 2014. Temperature alters food web body-size structure. Biol. Lett., 10, 1-5, doi: 10.1098/ rsbl.2014.0473.

Hampton S.E., 2004. Habitat overlaps of enemies: temporal patterns and the role of spatial complexity. Oecologia, 138, 475-484.

Hershey A.E. and Lamberti G.A., 2001. Aquatic insect ecology. In: Thorp J.H. and Covich A.P. (eds.), Ecology and Classification of North American Freshwater Invertebrates (2nd edn), Academic Press, San Diego, 733-775.

Holomuzki J.R., Collins J.P. and Brunkow P.E., 1994. Trophic control of fishless ponds by tiger salamander larvae. Oikos, $71,55-64$.

Jara F.G., 2014. Trophic ontogenetic shifts of the dragonfly Rhionaeschna variegata: the role of larvae as predators and prey in Andean wetland communities. Ann. Limnol. Int. J. Lim., 50, 173-184.

Jara F.G., Perotti M.G. and Diéguez M.C., 2012. Distribution of backswimmers in shallow ponds of Patagonia and their predatory role on a common tadpole-copepod assemblage. N.Z. J. Mar. Fresh., 46, 459-473.
Jara F.G., Úbeda C.A. and Perotti M.G., 2013. Predatory insects in lentic freshwater habitats from northwest Patagonia: richness and phenology. J. Nat. Hist., 47, 2749-2768.

Lancaster J. and Briers R.A. (eds.), 2008. Aquatic insects: challenges to populations. Proceedings of the Royal Entomological Society's 24th symposium, Cab International, Wallingford, $332 \mathrm{p}$.

Lancaster J. and Downes B.J., 2013. Aquatic Entomology (1st edn), Oxford University Press, Melbourne, Australia, $285 \mathrm{p}$.

Lundkvist E., Landin J., Jackson M. and Svensson C., 2003. Diving beetles (Dytiscidae) as predators of mosquito larvae (Culicidae) in field experiments and in laboratory tests of prey preference. B. Entomol. Res., 93, 219-226.

Maret T.J. and Collins J.P., 1996. Effect of prey vulnerability on population size structure of a gape-limited predator. Ecology, $77,320-324$.

Morin P.J., 1983. Predation, competition, and the composition of larval anuran guilds. Ecol. Monogr., 53, 119-138.

Nyström P. and Perez J.R., 1998. Crayfish predation on the common pond snail (Lymnaea stagnalis): the effect of habitat complexity and snail size on foraging efficiency. Hydrobiologia, 368, 201-208.

Ohba S., 2009. Ontogenetic dietary shift in the larvae of Cybister japonicus (Coleoptera: Dytiscidae) in Japanese rice fields. Environ. Entomol., 38, 856-860.

Ohba S., Miyasaka H. and Nakasuji F., 2008. The role of amphibian prey in the diet and growth of giant water bug nymphs in Japanese rice fields. Popul. Ecol., 50, 9-16.

Peckarsky B.L., 1982. Aquatic insects predator-prey relations. BioScience, 32, 261-266.

Perotti M.G., Diéguez M.C. and Jara F.G., 2005. Estado del conocimiento de humedales del norte patagónico (Argentina): aspectos relevantes e importancia para la conservación de la biodiversidad regional. Rev. Chil. Hist. Nat., 78, 723-737.

Persson L., Andersson J., Wahlstrom E. and Eklov P., 1996. Size-specific interactions in lake systems: predator gape limitation and prey growth rate and mortality. Ecology, 77, 900-911.

Raut S.K. and Saha T.C., 1989. The role of water bug Sphaerodema annulatum in the control of disease transmitting snails. J. Med. Appl. Malacol., 1, 97-106.

Schneider D.W. and Frost T.M., 1996. Habitat duration and community structure in temporary ponds. J. N. Am. Benthol. Soc., 15, 64-86.

Skelly D.K., 2002. Experimental venue and estimation of interaction strength. Ecology, 83, 2097-2101.

Smith C.K. and Petranka J.W., 1987. Prey size distributions and size-specific foraging success of Ambystoma larvae. Oecologia, 71, 214-239.

Sredl M.J. and Collins J.P., 1992. The interaction of predation, competition, and habitat complexity in structuring an amphibian community. Copeia, 3, 607-614.

Stav G., Blaustein L. and Margalit Y., 2000. Influence of nymphal Anax imperator (Odonata : Aeshnidae) on oviposition by the mosquito Culiseta longiareolata (Diptera : Culicidae) and community structure in temporary pools. J. Vector Ecol., 25, 190-202.

Stein R.A., Threlkeld S.T., Sandgren C.D., Sprules W.G., Persson L., Werner E.E., Neill W.E. and Dodson S.I., 1988. 
Size structured interactions in lake communities. In: Carpenter S.R. (ed.), Complex Interactions in Lake Communities, Springer Verlag, New York, 161-179.

Tarr T.L. and Babbitt K.J., 2002. Effects of habitat complexity and predator identity on predation of Rana clamitans larvae. Amphibia-Reptilia, 23, 13-20.

Travis J., Keen W.H. and Julianna J., 1985. The role of relative body size in a predator-prey relationship between dragonfly naiads and larval anurans. Oikos, 45, 59-65.

Trochine C., Modenutti B. and Balseiro E., 2006. Influence of spatial heterogeneity on predation by the flatworm Mesostoma ehrenbergii (Focke) on calanoid and cyclopoid copepods. J. Plankton Res., 28, 267-274.

Trochine C., Balseiro E. and Modenutti B., 2008. Zooplankton of fishless ponds of Northern Patagonia: insights into predation effects of Mesostoma ehrenbergii. Int. Rev. Hydrobiol., 93, 312-327.

Turner A.M. and Chislock M.F., 2007. Dragonfly predators influence biomass and density of pond snails. Oecology, 153, 407-415.

Urban M.C., 2007. Predator size and phenology shape prey survival in temporary ponds. Oecologia, 154, 571-580.

Urban M.C., 2008. The evolution of prey body size reaction norms in diverse communities. J. Anim. Ecol., 77, 346-355.

Vega M., 1995. Morphology and defense structures in the predator-prey interaction: an experimental study of Parabroteas sarsi (Copepoda, Calanoida) with different cladoceran preys. Hydrobiologia, 299, 139-145.

Vega M., 1998. Impact of Parabroteas sarsi (Copepoda: Calanoida) predation planktonic cladocerans in pond of Southern Andes. J. Freshw. Ecol., 13, 383-389.
Vega M.P., 1999. Life-stage differences in the diet of Parabroteas sarsi (Daday)(Copepoda, Calanoida): a field study. Limnologica, 29, 186-190.

Wellborn G.A., Skelly D.K. and Werner E.E., 1996. Mechanisms creating community structure across a freshwater habitat gradient. Ann. Rev. Ecol. Syst., 27, 337-363.

Wilbur H.M., 1987. Regulation of structure in complex systems: experimental temporary pond communities. Ecology, 68, 1437-1452.

Wilbur H.M., 1997. Experimental ecology of food webs: complex systems in temporary ponds. The Robert H. Mac-Arthur Award lecture. Ecology, 78, 2279-2302.

Wilbur H.M. and Fauth J.E., 1990. Experimental aquatic food webs: interactions between two predators and two prey. Am. Nat., 135, 176-204.

Williams D.D., 2006. The Biology of Temporary Waters, Oxford University Press, Oxford, 337 p.

Winkelmann C., Hellmann C., Worischka S., Petzoldt T. and Benndorf J., 2011. Fish predation affects the structure of a benthic community. Freshwater Biol., 56, 1030-1046.

Woodward G. and Hildrew A.G., 2002. Body-size determinants of niche overlap and intraguild predation within a complex food web. J. Anim. Ecol., 71, 1063-1074.

Wright J.F., Sutcliffe D.W. and Furse M.T., 2000. Assessing the Biological Quality of Fresh Waters -RIVPACS and Other Techniques, Freshwater Biological Association, Ambleside, Cumbria, UK, $373 \mathrm{p}$.

Zhang J., Xie P., Tao M., Guo L., Chen J., Li L., Zhang X. and Zhang L., 2013. The impact of fish predation and cyanobacteria on zooplankton size structure in 96 subtropical lakes. PLOS ONE 8(10), e76378. doi: 10.1371/journal. pone. 0076378 